\title{
\begin{tabular}{l|l} 
Mibraries & DSpace@MIT
\end{tabular}
}

\author{
MIT Open Access Articles
}

\section{Highly Selective Heterogeneous Ethylene Dimerization with a Scalable and Chemically Robust MOF Catalyst}

The MIT Faculty has made this article openly available. Please share how this access benefits you. Your story matters.

Citation: Metzger, Eric D. et al. "Highly Selective Heterogeneous Ethylene Dimerization with a Scalable and Chemically Robust MOF Catalyst." ACS Sustainable Chemistry \& Engineering 7, 7 (March 2019): 6654-6661 (C) 2019 American Chemical Society

As Published: http://dx.doi.org/10.1021/acssuschemeng.8b05703

Publisher: American Chemical Society (ACS)

Persistent URL: https://hdl.handle.net/1721.1/128212

Version: Author's final manuscript: final author's manuscript post peer review, without publisher's formatting or copy editing

Terms of Use: Article is made available in accordance with the publisher's policy and may be subject to US copyright law. Please refer to the publisher's site for terms of use. 


\section{Highly Selective Heterogeneous Ethylene}

\section{Dimerization with a Scalable and Chemically Robust}

\section{MOF Catalyst}

Eric D. Metzger, ${ }^{1,+}$ Robert J. Comito, ${ }^{1,+}$ Zhenwei $W u,{ }^{2}$ Guanghui Zhang, ${ }^{2}$ Romain C. Dubey, ${ }^{1,+}$

Wei Xu, ${ }^{3}$ Jeffrey T. Miller, ${ }^{2}$ Mircea Dincă ${ }^{1 *}$

${ }^{1}$ Department of Chemistry, Massachusetts Institute of Technology, 77 Massachusetts Avenue, Cambridge, Massachusetts 02139, United States.

${ }^{2}$ Davidson School of Chemical Engineering, Purdue University, 480 Stadium Mall Dr., West Lafayette, Indiana, 47907, United States.

${ }^{3}$ Saudi Aramco, Chemicals R\&D Laboratory, Innovation Cluster III, King Abdullah University of Science and Technology (KAUST), Thuwal 23955-6900, Saudi Arabia

*Corresponding Author: mdinca@mit.edu

E.D.M. and R.J.C. contributed equally to this work. 


\begin{abstract}
Metal-organic frameworks (MOFs) hold great promise as structurally tunable catalysts capable of high selectivity in the solid state, yet their comparatively high cost and often limited stability remain significant concerns for their commercialization as heterogeneous catalysts. Here, we report detailed X-ray absorption spectroscopy studies of Co- and Ni-MFU-4l, a class of highly selective MOF catalysts for olefin upgrading, and reveal mechanisms that lead to their deactivation. We further show that Ni-CFA-1, a more scalable and economical alternative to NiMFU-4l, reproduces both the local coordination structure and the high selectivity of the latter in ethylene dimerization catalysis. Under optimal conditions, Ni-CFA-1 activated by MMAO-12 achieves a turnover frequency of 37,100 per hour and a selectivity of $87.1 \%$ for 1 -butene, a combination of activity, selectivity, and affordability that is unmatched among heterogeneous ethylene dimerization catalysts. Ni-CFA-1 retains its high activity for at least 12 hours in a oneliter semi-batch reactor, offering a strategy toward robust and scalable MOFs for industrial catalysis.
\end{abstract}

Keywords: Ethylene dimerization, catalyst deactivation, heterogeneous catalysis, catalyst lifetime, X-ray absorption spectroscopy 


\section{Introduction}

Owing to the processing advantages of textural control and catalyst recovery, heterogeneous catalysis remains the industry standard, with a commercial significance that cannot be over-stated. Yet the structural polydispersity and inflexibility of inorganic solid catalysts severely limits the study and optimization of their catalytic selectivity. Consequently, industrial processes that require high purity product streams often rely on discrete molecular catalysts, operating under more demanding and costly homogeneous conditions.

Metal-organic frameworks (MOFs) are structurally monodisperse and tunable materials that offer the capacity for molecular-level control in the solid state. They have attracted considerable attention as single-site heterogeneous catalysts, ${ }^{1-10}$ amenable to synthetic modification, mechanistic analysis, and exceptional catalytic selectivity. Nevertheless, these molecule-like properties of MOFs come at the price of using an organic linker as a repeating structural unit, typically more expensive than purely inorganic solids.

Furthermore, the coordination networks of which MOFs are composed often lack the thermal, chemical, or mechanical resilience required for the demanding conditions of industrial catalysis. ${ }^{4,11}$ Along these lines, numerous reports have addressed the cost and instability of MOFs through the design of new organic linkers ${ }^{12}$ or inorganic nodes. ${ }^{13-15}$ However, this approach would be unlikely to preserve the reactivity of a promising but impractical MOF catalyst.

In recent years metal-organic frameworks have demonstrated promise as catalysts for olefin oligomerization and polymerization. These reactions are performed under air-free conditions at relatively mild temperatures and pressures, making them particularly well-suited for MOF catalysis. Typically, MOF-based catalysts are prepared by employing catalytically active 
metalloligands, ${ }^{16,17}$ post-synthetically appending molecularly defined catalysts to the MOF, ${ }^{6,18,19}$ or depositing metal atoms or clusters in the MOFs. ${ }^{20-23}$ In contrast, our laboratory and others ${ }^{24,25}$ have developed MOFs with catalytically active metal nodes. We have reported several catalysts for the selective polymerization and oligomerization of light olefins prepared by cation exchange in MFU-4l (MFU-4l $=\mathrm{Zn}_{5} \mathrm{Cl}_{4}(\mathrm{BTDD})_{3} ; \mathrm{H}_{2} \mathrm{BTDD}=\operatorname{bis}(1 H-1,2,3$-triazolo[4,5-b],[4',5'i])dibenzo[1,4]dioxin). ${ }^{26-29}$ This azolate MOF serves as an excellent platform for studying organometallic catalysis in the solid state, with a monodisperse and highly symmetric structure featuring scorpionate-like coordination of $\mathrm{Zn}^{2+}$ ions. These ions undergo exchange with a variety of transition metal cations under mild conditions, ${ }^{30-33}$ providing a predictable method to introduce catalytic sites in a molecule-like environment in the solid state. Based on this strategy, we reported the highly selective dimerization of ethylene to 1-butene using Ni-MFU-4l (1) ${ }^{27}$ the highly stereoselective polymerization of 1,3-butadiene using Co-MFU-4l (2), ${ }^{29}$ and the single-site polymerization of ethylene with Ti-, V-and Cr-MFU-4l. ${ }^{28,34}$ However, the scalability of MFU-4l is limited by both the expensive, multistep synthesis of its linker $\mathrm{H}_{2} \mathrm{BTDD}$, and the high-dilution conditions required for its crystallization, which requires the use of a large volume of solvent. Partly because of these limitations, key mechanistic details including the mode of catalyst activation and deactivation have not previously been established, despite the obvious significance of such studies for understanding and extending catalyst lifetime. 


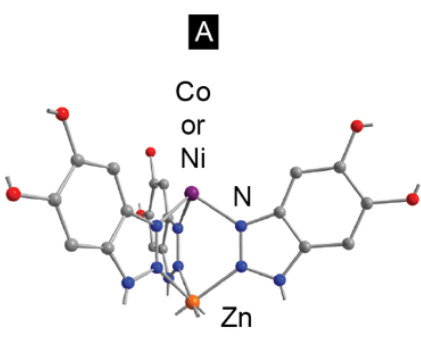

Ni- and Co-MFU-4I (1 and 2)

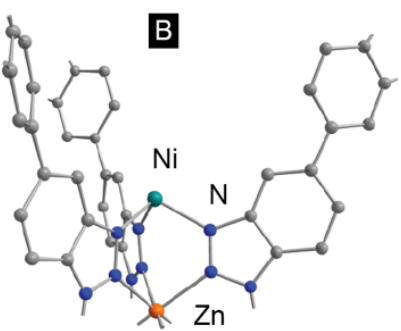

Ni-CFA-1 (3)
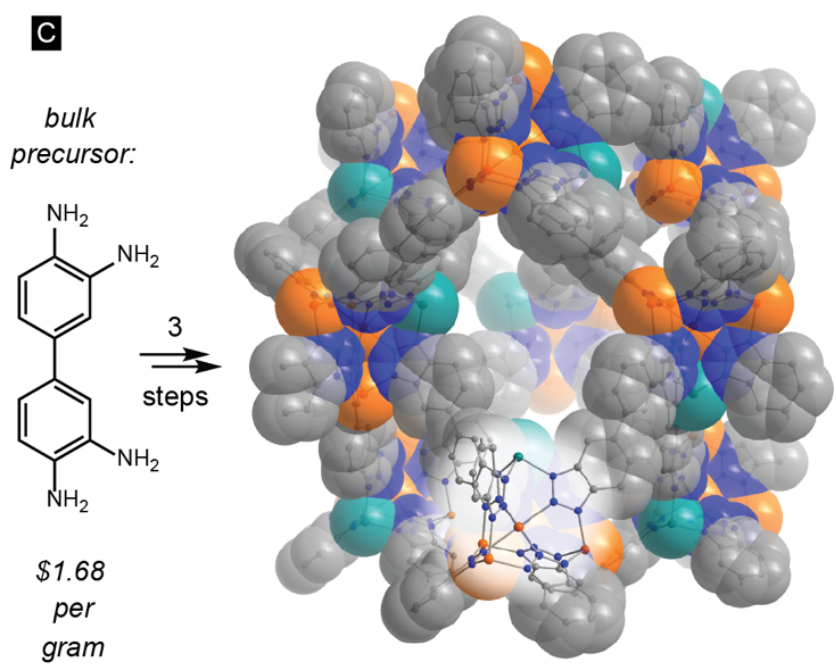

Ni-CFA-1 (3): a scalable MOF catalyst

Figure 1. A) Related $\mathrm{Ni}^{2+}$ and $\mathrm{Co}^{2+}$ sites in $\mathbf{1}$ and $\mathbf{2}$ respectively. B) $\mathrm{Ni}^{2+}$ site in 3. C) Three-dimensional structure of 3. Extraframework anions were removed for clarity.

Here, we characterize a unique reductive demetallation process as the basis for deactivation in $\mathrm{Ni}$ and Co-MFU-4l (1 and 2; Figure 1A) using X-ray absorption spectroscopy (XAS). Taking advantage of the modular structure of MOFs, we develop Ni-CFA-1 (3; Figures 1B and 1C) as a more synthetically accessible catalyst that closely reproduces the scorpionate-like nickel site of $\mathbf{1}$. We show that Ni-CFA-1 reproduces the high selectivity and activity of Ni-MFU-4l for the dimerization of ethylene to 1-butene in a more scalable material. Finally, we demonstrate a largerscale operation by employing Ni-CFA-1 in a one-liter reactor where high activity is retained for over 12 hours. 


\section{Results and Discussion}

To gain insight into the deactivation of $\mathbf{1}$ and $\mathbf{2}$ with the aim of increasing catalyst lifetime, we isolated samples of both materials from ethylene dimerization and diene polymerization conditions respectively (i.e. both involving MMAO-12, toluene, and olefinic substrate). For comparison, samples of $\mathbf{1}$ and $\mathbf{2}$ were treated with alkylaluminum cocatalysts in the absence of substrate. Samples of $\mathbf{1}$ were then analyzed by Ni and Zn K-edge XAS, while samples of $\mathbf{2}$ were analyzed by Co K-edge XAS. For additional comparison, we also analyzed native MFU-4l (i.e. zinc-only) after treatment with $\mathrm{AlMe}_{3}$ by Zn K-edge XAS.

Collectively, the resulting XAS analysis implicates reductive demetallation to metallic cobalt and nickel as the ultimate decomposition pathway for $\mathbf{1}$ and $\mathbf{2}$, respectively. Specifically, the cobalt Kedge XAS data show an isosbestic progression from Co-MFU-4l to cobalt metal (Figure 2A). Indeed, X-ray absorption fine structure analysis (EXAFS) of the most deactivated sample (CoMFU-4l exposed to $\mathrm{AlMe}_{3}$ for 14 hours, 4) resulted in a k-space plot nearly identical to that of metallic cobalt foil but reduced in intensity (Figure 2B). These data indicate a near-quantitative conversion of the $\mathrm{Co}^{2+}$ ions in $\mathbf{2}$ to cobalt nanoparticles in 4. Qualitatively, nickel K-edge XAS data show a similar progression from 1 to nickel metal, although the lack of isosbestic points suggests that other intermediates may occur (Figure 2C). Nevertheless, EXAFS analysis suggests Ni-Ni scattering consistent with partial formation of metallic nickel (Figure S11). 

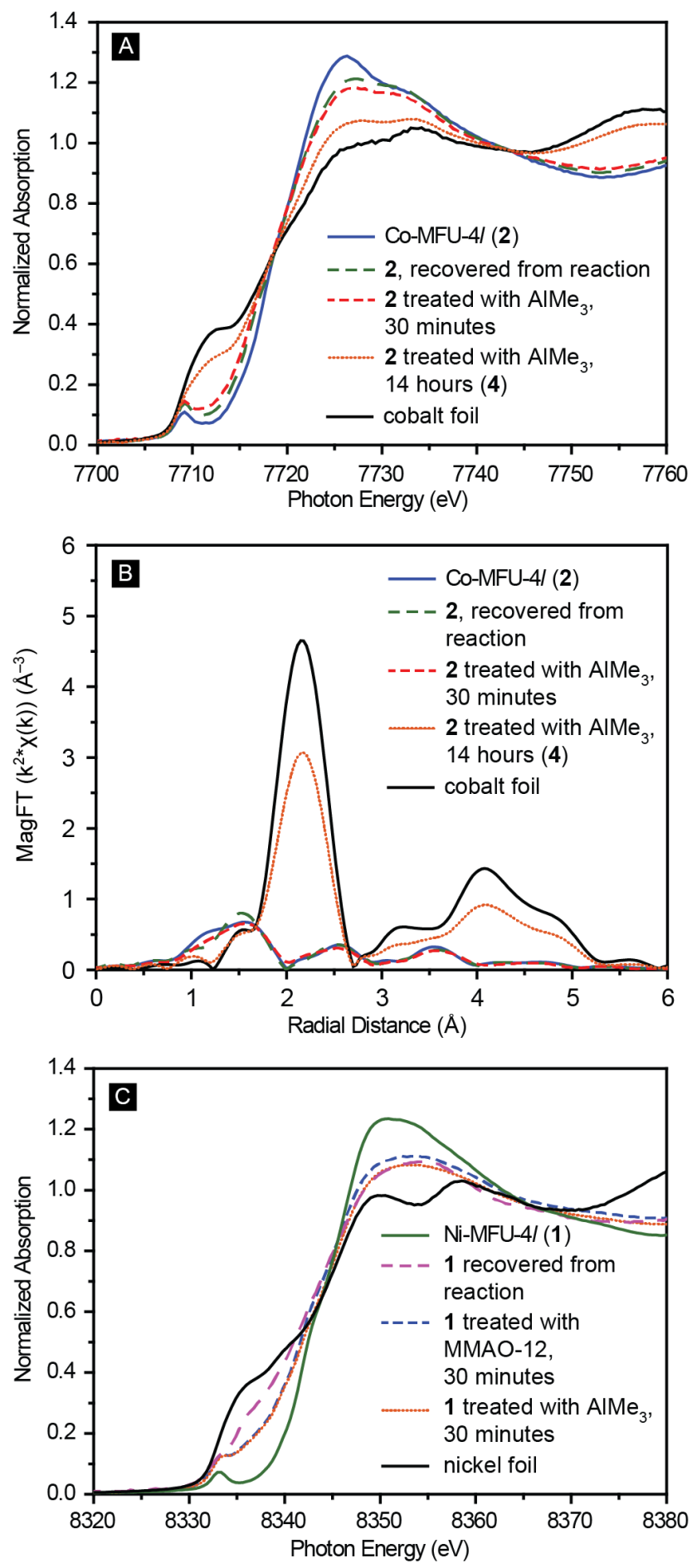

Figure 2. A) Cobalt K-edge XAS analysis of recovered samples of 2. B) EXAFS comparison of cobalt-containing samples. C) Nickel K-edge XAS analysis of recovered samples of $\mathbf{1}$.

In contrast, the Zn K-edge XAS analysis does not show reduction of zinc(II) to metallic zinc in $\mathbf{1}$ or in native MFU-4l (Figure 3). ${ }^{35}$ Instead, all of the chemically treated samples show a similar 
reduction in edge energy (Table S1) to values close to that of diethylzinc $(9661.8 \mathrm{eV})^{36}$ and a decrease in white line intensity relative to pristine MFU-4l (Figure 3). EXAFS analysis of the Zn K-edge data shows no new peak in the range $\mathrm{R}=2.0-2.5 \AA$ (phase-uncorrected distance), as would arise for Zn-Zn scattering in metallic Zn (Figure S12). Together, these data are more consistent with partial alkylation of zinc(II) sites than reductive demetallation. In addition, PXRD analysis shows good retention of crystallinity for MFU- $4 l$ treated with $\mathrm{AlMe}_{3}$, even after exposure to air (Figure S6). Given that mixtures of MFU-4l and alkylaluminums are not reactive toward ethylene, we propose that the alkylation of zinc sites in $\mathbf{1}$ is a benign side reaction during ethylene oligomerization, which consumes cocatalyst but does not impact the stability or reactivity of the MOF.

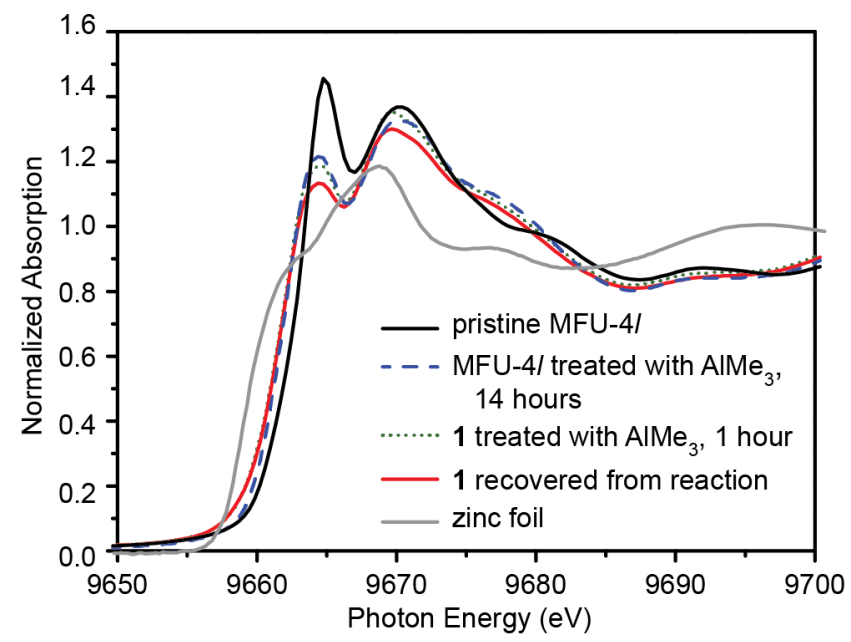

Figure 3. Zinc K-edge XAS analysis of MFU-41 and Ni-MFU-4l after treatment with alkylaluminums.

To account for the reductive demetallation of $\mathrm{Ni}^{2+}$ and $\mathrm{Co}^{2+}$ to metal, we propose the insertion of alkylaluminum units into the secondary building unit sites vacated by $\mathrm{Ni}^{2+}$ or $\mathrm{Co}^{2+}$ ions, respectively, and the formation of aluminum scorpionate moieties (Scheme 1). Consistent with this hypothesis, ICP-MS analysis of native MFU-4l after treatment with $\mathrm{AlMe}_{3}$ for 14 hours shows only trace aluminum content, while similarly treated $\mathbf{1}$ and $\mathbf{2}$ show superstoichiometric 
incorporation of aluminum (section S3). Furthermore, PXRD analysis shows that $\mathbf{4}$ remains highly crystalline when analyzed under air-free conditions, but loses crystallinity rapidly upon exposure to air (Figure S4), as would be expected if reactive scorpionate alkyl-aluminum species in 4 were exposed to air. By contrast, exposure of $\mathbf{4}$ to air results only in a very minor change in the cobalt K-edge XAS spectrum (Figure S10). Together, these data suggest that structural collapse is not the result of cobalt oxidation but may result from the reaction of an air-sensitive scorpionate alkylaluminum unit (Scheme 1; 5). As precedent for this substitution, potassium and thalium tris(pyrazolyl)borate complexes both react with trimethylaluminum to generate discrete scorpionate alkylaluminum complexes and potassium or thalium metal. ${ }^{37,38}$ To evaluate the relevance of this reductive substitution in $\mathbf{1}$ and $\mathbf{2}$, we combined $\mathrm{AlMe}_{3}$ with $\mathrm{Tp}^{\mathrm{Mes}} \mathrm{NiCl}$ and $\mathrm{Tp}^{\mathrm{Mes}} \mathrm{CoCl}\left(\mathrm{Tp}^{\mathrm{Mes}-}=\right.$ tris(3-mesityl-1-pyrazolyl)borate), molecular scorpionate complexes shown to reproduce the catalytic selectivity of $\mathbf{1}$ and $\mathbf{2}$ respectively. ${ }^{29,39}$ In both cases, nickel or cobalt metal are indeed produced along with a soluble aluminum tris(pyrazolyl)borate complex, although pure aluminum complexes were not isolated (section S5).
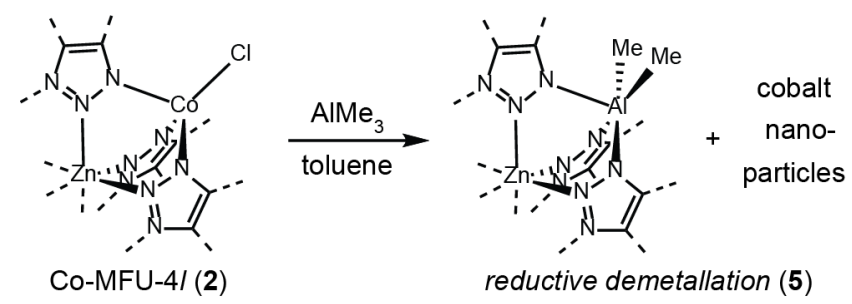

Scheme 1. Proposed mechanism for the deactivation of $\mathbf{2}$ in the presence of alkylaluminum cocatalysts.

With the mechanistic insight that the deactivation of $\mathbf{1}$ and $\mathbf{2}$ is a reductive demetallation heavily influenced by the metal cluster, we realized that the lifetimes of $\mathbf{1}$ and $\mathbf{2}$ were intrinsically limited by the chemistry of these MOFs. Instead, we turned our efforts towards the development of a more economical and scalable ethylene dimerization catalyst. Although MFU- $4 l$ and CFA-1 are not 
isoreticular, the node of CFA-1 $\left(\mathrm{CFA}-1=\mathrm{Zn}_{5}(\mathrm{OAc})_{4}(\mathrm{bibtz})_{3}\right)$ is structurally homologous to that of MFU-4l. ${ }^{30,40}$ Importantly, CFA-1 is constructed from a much more synthetical accessible and therefore more scalable linker $\mathrm{H}_{2}$ bibtz $\left(\mathrm{H}_{2}\right.$ bibtz $=1 H, 1^{\prime} H-5,5^{\prime}$-bibenzo[d] $[1,2,3]$ triazole $)$. This ligand can be prepared in a single, high-yielding step from commercially available 3,3'diaminobenzidine (Figure 1), already used industrially in the preparation of polybenzimidazole fibers. Indeed, our cost comparison shows that this ligand is more than forty times cheaper than that used in the preparation of Ni-MFU-4l (section S6.4). On this basis, we anticipated that incorporation of $\mathrm{Ni}^{2+}$ into CFA-1 would provide a more synthetically accessible but otherwise analogous heterogeneous catalyst for the selective dimerization of ethylene. Indeed, under conditions analogous to those used for preparing Ni-MFU-4l, soaking CFA-1 in solutions of $\mathrm{Ni}\left(\mathrm{NO}_{3}\right)_{2} \cdot 6 \mathrm{H}_{2} \mathrm{O}$ and DMF provided efficient incorporation of nickel, as determined by ICP-MS. ${ }^{41}$ Furthermore, powder X-ray diffraction (Figure S17) and gas sorption analysis (Figure S16) demonstrate excellent retention of crystallinity and porosity in Ni-CFA-1 (3).

Most relevantly, $\mathbf{3}$ retains the high activity and selectivity of $\mathbf{1}$ for ethylene dimerization. Initial catalyst evaluation was performed in a $50 \mathrm{~mL}$ stainless steel Parr reactor using MMAO-12 and $\mathrm{Ni}(7.5 \%)-\mathrm{CFA}-1$, a sample of $\mathbf{3}$ in which nickel accounts for $7.5 \%$ of the molar metal content. In a typical run, MMAO-12 was added to a stirring suspension of $\mathbf{3}$ and toluene, followed by ethylene pressurization. After the desired time interval, the reaction was rapidly cooled in a dry ice/acetone bath, vented, and quenched with ice-cold water. With 1000 equivalents of MMAO-12 and 25 bar of ethylene, 3 shows a turnover frequency (TOF) of 16,600 moles of ethylene consumed per mole of nickel per hour (Table 1, entry 15), and a selectivity of $95.1 \%$ for dimers and $83.1 \%$ for 1 butene. 
In order to confirm the immobilized nickel sites as the basis for catalysis, we performed several control experiments. First, subjection of CFA-1 to similar reaction conditions did not lead to observable dimerization activity, indicating that nickel incorporation is required for catalysis. Next, the supernatant of the reaction and of the mixture 3/MMAO-12 were separated by air free filtration. ICP-MS analysis of the supernatant demonstrated minimal leaching of soluble nickel species $(<1 \% \mathrm{~mol} / \mathrm{mol}$ of nickel content). Finally, after resubjecting these supernatants to reaction conditions we observed no dimerization reactivity, evidencing the heterogeneous nature of the nickel catalyst. As an additional test, $\mathbf{3}$ displayed no ethylene dimerization activity in the absence of alkylaluminum cocatalyst.
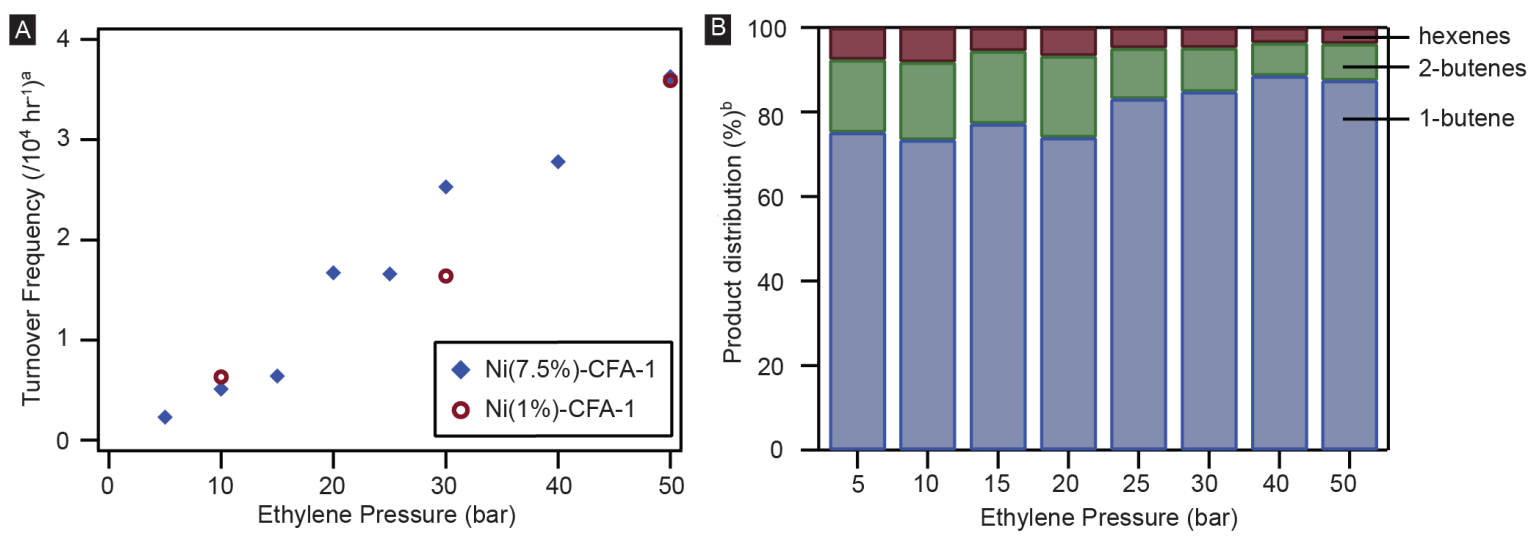

C

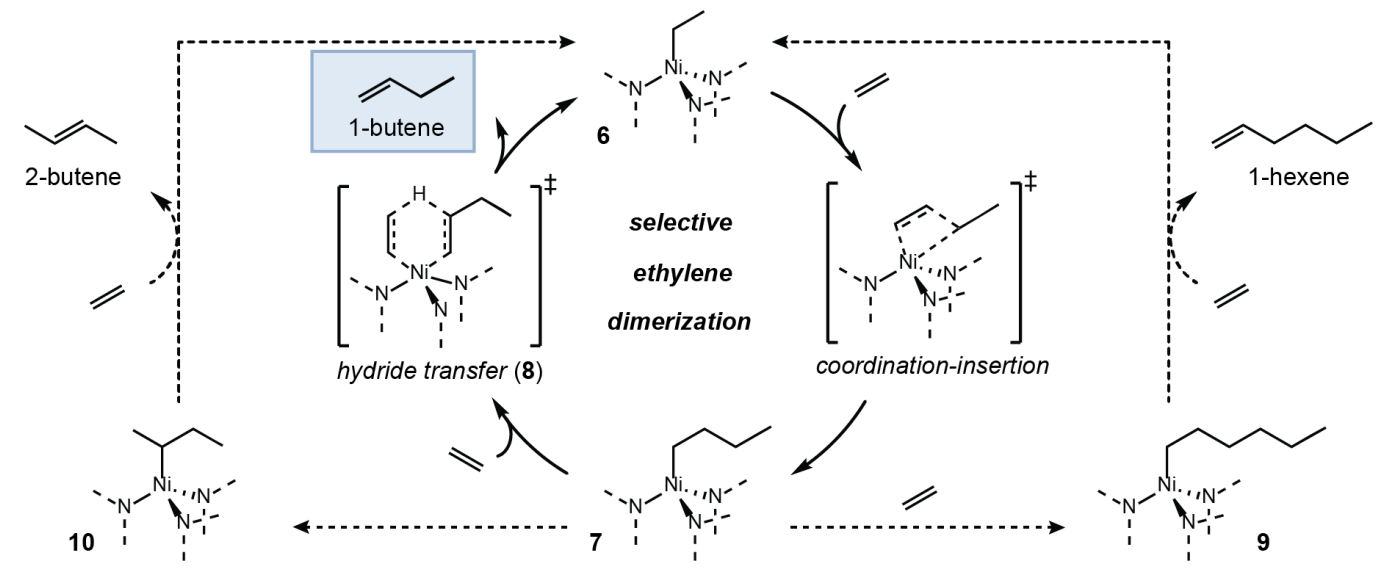

Figure 4. A) The pressure dependence of ethylene dimerization with Ni(7.5\%)-CFA-1 and Ni(1\%)-CFA-1. B) The product distribution at various ethylene pressures for $\mathrm{Ni}(7.5 \%)$-CFA-1 with 1000 equivalents of MMAO-12, demonstrating the increased selectivity for 1-butene at higher pressures. C) The proposed mechanism for ethylene dimerization with Ni-CFA-1. ${ }^{a} \mathrm{Moles}$ of ethylene consumed per mole of Ni per hour, determined by GC. ${ }^{b}$ Weight fraction of the total liquid product distribution as determined by GC. 
Table 1. Ethylene dimerization with Ni-CFA-1. ${ }^{a}$

Selectivity (wt \%)

\begin{tabular}{|c|c|c|c|c|c|c|c|c|c|}
\hline \multirow[b]{2}{*}{ Entry } & \multirow[b]{2}{*}{$\begin{array}{c}\text { Nickel } \\
\text { Loading }\end{array}$} & \multirow[b]{2}{*}{$\begin{array}{c}\text { Pressure } \\
\text { (bar) }\end{array}$} & \multirow[b]{2}{*}{$\begin{array}{c}\mathbf{T} \\
\left({ }^{\circ} \mathbf{C}\right)^{b}\end{array}$} & \multirow[b]{2}{*}{$\begin{array}{l}\text { MMAO-12 } \\
\text { equivalents }\end{array}$} & \multirow[b]{2}{*}{$\begin{array}{c}\text { MMAO-12 } \\
\text { concentration } \\
(\mathrm{M})\end{array}$} & \multirow[b]{2}{*}{$\begin{array}{l}\text { TOF } \\
\left(\mathbf{h}^{-1}\right)^{c}\end{array}$} & \multicolumn{3}{|r|}{$(w t \%)$} \\
\hline & & & & & & & $\mathrm{C}_{4}{ }^{d}$ & $\alpha-C_{4}{ }^{e}$ & $\begin{array}{c}\text { Overall } \\
\text { 1-butene }\end{array}$ \\
\hline 1 & $7.5 \%$ & 50 & 22 & 50 & 0.03 & 13100 & 87.7 & 93.9 & 82.4 \\
\hline 2 & $7.5 \%$ & 50 & 22 & 100 & 0.05 & 17900 & 94.6 & 93.2 & 88.2 \\
\hline 3 & $7.5 \%$ & 50 & 22 & 200 & 0.08 & 29000 & 93.3 & 90.7 & 84.6 \\
\hline 4 & $7.5 \%$ & 50 & 22 & 250 & 0.10 & 30600 & 94.2 & 91.3 & 86.0 \\
\hline 5 & $7.5 \%$ & 50 & 22 & 500 & 0.13 & 31200 & 96.6 & 94.4 & 91.2 \\
\hline 6 & $7.5 \%$ & 50 & 22 & 1000 & 0.33 & 36300 & 96.2 & 91.0 & 87.5 \\
\hline 7 & $7.5 \%$ & 50 & 22 & 2000 & 0.49 & 37100 & 95.5 & 91.2 & 87.1 \\
\hline 8 & $7.5 \%$ & 50 & 0 & 1000 & 0.30 & 13700 & 97.9 & 98.2 & 96.1 \\
\hline 9 & $7.5 \%$ & 50 & 22 & 1000 & 0.33 & 36300 & 96.2 & 91.0 & 87.5 \\
\hline 10 & $7.5 \%$ & 50 & 50 & 1000 & 0.29 & 900 & 92.6 & 80.9 & 74.9 \\
\hline 11 & $7.5 \%$ & 5 & 22 & 1000 & 0.25 & 2300 & 92.4 & 81.4 & 75.2 \\
\hline 12 & $7.5 \%$ & 10 & 22 & 1000 & 0.26 & 5100 & 91.8 & 80.0 & 73.4 \\
\hline 13 & $7.5 \%$ & 15 & 22 & 1000 & 0.20 & 6400 & 94.5 & 81.7 & 77.2 \\
\hline 14 & $7.5 \%$ & 20 & 22 & 1000 & 0.35 & 16700 & 93.3 & 79.3 & 74.0 \\
\hline 15 & $7.5 \%$ & 25 & 22 & 1000 & 0.20 & 16600 & 95.1 & 87.4 & 83.1 \\
\hline 16 & $7.5 \%$ & 30 & 22 & 1000 & 0.27 & 25300 & 95.2 & 89.1 & 84.8 \\
\hline 17 & $7.5 \%$ & 40 & 22 & 1000 & 0.20 & 27800 & 96.4 & 91.9 & 88.6 \\
\hline 18 & $7.5 \%$ & 50 & 22 & 1000 & 0.33 & 36300 & 96.2 & 91.0 & 87.5 \\
\hline 19 & $1 \%$ & 50 & 22 & 100 & 0.01 & 0 & --- & --- & --- \\
\hline 20 & $1 \%$ & 50 & 22 & 500 & 0.03 & 1800 & 88.6 & 87.8 & 77.8 \\
\hline 21 & $1 \%$ & 50 & 22 & 1000 & 0.05 & 16200 & 95.9 & 92.9 & 89.1 \\
\hline 22 & $1 \%$ & 50 & 22 & 2000 & 0.11 & 33300 & 96.6 & 96.6 & 93.3 \\
\hline 23 & $1 \%$ & 50 & 22 & 5000 & 0.24 & 36100 & 94.9 & 94.7 & 89.9 \\
\hline 24 & $1 \%$ & 10 & 22 & 5000 & 0.25 & 6400 & 92.4 & 90.8 & 83.9 \\
\hline 25 & $1 \%$ & 30 & 22 & 5000 & 0.24 & 16500 & 94.2 & 96.1 & 90.5 \\
\hline 26 & $1 \%$ & 50 & 22 & 5000 & 0.24 & 36100 & 94.9 & 94.7 & 89.9 \\
\hline
\end{tabular}

${ }^{a}$ As determined by GC analysis. ${ }^{b}$ Initial reaction temperature as measured by an internal temperature probe. ${ }^{c}$ moles of ethylene converted per mole of nickel per hour, determined by GC analysis. ${ }^{d}$ Percent of oligomeric products that are $\mathrm{C}_{4}$ olefins. ${ }^{e}$ Percent $1-$ butene relative to all $\mathrm{C}_{4}$ products. ${ }^{f}$ The overall selectivity for 1-butene among all oligomeric products. 
Indeed, the activity of $\mathbf{3}$ depends significantly on both the composition and loading of cocatalyst. As was the case with 1, 3 shows high reactivity in combination with MMAO-12, although no dimerization activity is observed with trimethylaluminum. However, AlMe-depleted MMAO$12^{42}$ provides significantly reduced activity relative to commercial MMAO-12 solutions that contain residual $\mathrm{AlMe}_{3}$. Furthermore, with commercial MMAO-12, the activity increases monotonically with the $\mathrm{Al}$ to Ni ratio (Table 1, entries 1-7), although the benefit of additional aluminum is reduced when the $\mathrm{Al}: \mathrm{Ni}$ ratio exceeds $\sim 250$. As a plausible mechanism, the high concentration of MMAO-12 may be required to promote cocatalyst diffusion into the porous structure of 3. Along these lines, residual $\mathrm{AlMe}_{3}$ may serve to improve diffusion into the MOF by decreasing the average aggregation size of MMAO-12. Indeed the viscosity-average molecular weight of MAO has been shown to decrease significantly with the addition of substoichiometric $\mathrm{AlMe}_{3}{ }^{43}$ On the other hand, cocatalyst loading does not significantly affect selectivity toward 1butene, except at low $\mathrm{Al}$ : Ni ratios.

In contrast, the applied ethylene pressure significantly influences both the activity and selectivity of polymerization catalyst 3. At ethylene pressures ranging between 5 and $50 \mathrm{bar}$, there is an apparent linear dependence of turnover frequency on pressure and a weaker but positive dependence of both chain- and regioselectivity on pressure (Table 1, entries 11-18; Figure 4). To interpret this data kinetically, we first sought to rule out mass transport limitations by comparing the activity of both $\mathrm{Ni}(7.5 \%)$ - and $\mathrm{Ni}(1 \%)$-CFA-1 over this pressure range (Figure $4 \mathrm{~A}$ ). The consistency of their TOF versus pressure curves suggests that local depletion of monomer does not bias the activity data. Consequently, the first-order dependence of activity on monomer concentration implicates a coordination-insertion mechanism for chain growth, as previously demonstrated for 1/MMAO-12. ${ }^{26}$ Likewise, our selectivity data is most consistent with hydride 
transfer to monomer, ${ }^{44,45}$ a chain termination process commonly invoked for nickel-catalyzed ethylene polymerization. ${ }^{46,47}$ Thus, dimerization would involve ethylene insertion into ethylnickel 6 to generate butylnickel 7 (Figure 4C). Subsequent chain transfer to ethylene (8), providing 1butene and regenerating $\mathbf{6}$, would be accelerated at higher ethylene pressure relative to secondary insertion to hexylnickel 9 or chain walking to isobutylnickel $\mathbf{1 0}$.

Upon evaluating the influence of temperature on reactivity, we found that $3 / \mathrm{MMAO}-12$ is much more active at $25{ }^{\circ} \mathrm{C}$ than at either $0{ }^{\circ} \mathrm{C}$ or $50{ }^{\circ} \mathrm{C}$ (Table 1 , entries 8-10). However, selectivity increases considerably to $96.1 \% 1$-butene at $0{ }^{\circ} \mathrm{C}$ and decreases considerably to $74.9 \% 1$-butene at $50{ }^{\circ} \mathrm{C}$. In light of our proposed mechanism, we attribute the rapid drop in selectivity at higher temperatures both to a decrease in ethylene concentration and an entropic preference for unimolecular chain walking over bimolecular chain transfer.

Having identified $\mathbf{3}$ as a scalable and highly selective catalyst for ethylene dimerization, we next sought to evaluate its performance in a $1 \mathrm{~L}$ stainless steel reactor emulating industrial olefin dimerization. Initially, we found that our optimal conditions with Ni(7.5\%)-CFA-1 and MMAO12 scaled poorly, resulting in spontaneous heating and early catalyst deactivation. Nevertheless, the use of $\mathrm{Ni}(1 \%)-\mathrm{CFA}-1$ and an internal cooling coil more efficiently regulated the temperature of the exothermic dimerization reaction at this larger scale. Under conditions optimized for this catalyst on a $5 \mathrm{~mL}$ scale, a semi-batch dimerization process was allowed to continue in a one-liter reactor for 96 hours with continuous sampling for GCMS analysis (Figure 5, section S7.3). The resulting time course shows excellent retention of catalytic activity for 18 hours, followed by a gradual decrease in catalytic activity out to 48 hours and a maximum turnover of 400,000 moles of ethylene per mole of nickel. Overall selectivity for 1-butene remains high $(72.2 \%$ selective for 1-butene; $82.4 \%$ selective for dimers, $87.6 \%$ selective for 1-butene among dimers), although we 
observe a progressive decrease in both chain and regioselectivity that we attribute to secondary reactivity by the accumulating 1-butene.

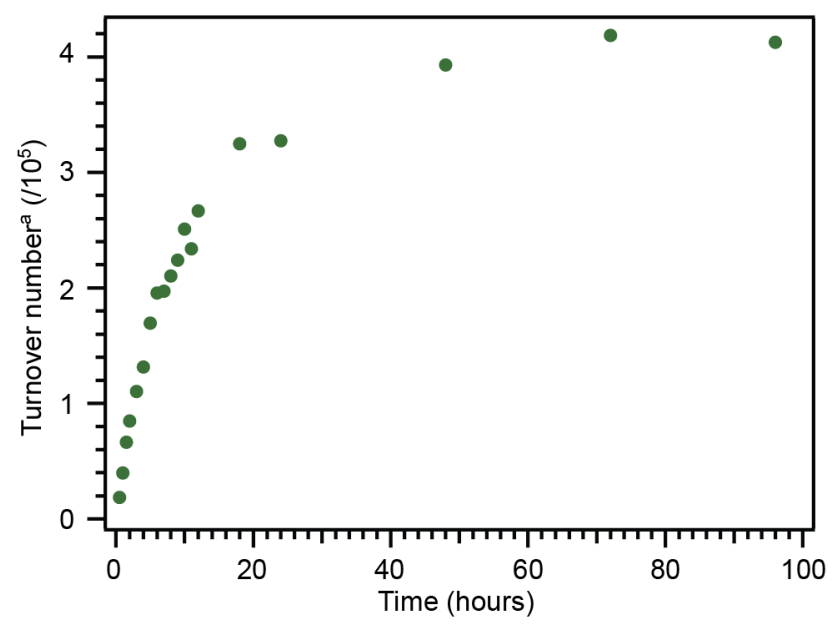

Figure 5. Time course analysis of an extended ethylene dimerization reaction. Performed with Ni(1\%)-CFA-1, MMAO-12 (64,000 $: 1, \mathrm{Al}: \mathrm{Ni}$ ), and 50 bar of ethylene on a $400 \mathrm{~mL}$ scale. ${ }^{a}$ Moles of ethylene consumed per mole of Ni, determined by GC.

To study catalyst decomposition in the CFA-1 system, ethylene dimerization was repeated in several batches on a small scale, isolating the resulting solids by filtration at various time points. PXRD analysis of the resulting solids shows excellent retention of crystallinity for the first 8 hours, followed by a graduate decrease in crystallinity consistent with our proposed catalyst deactivation mechanism determined for MFU-4l (Figure S17). Notably, this analysis also showed only minor accumulation of polyethylene ( $<1 \%$ yield of polyolefin products) which exhibits a free-flowing powder morphology that reduces the risk for polymer-based reactor fouling, in contrast to the polymeric byproducts typical with homogeneous catalysts. Furthermore, industrial homogeneous catalysts for ethylene dimerization deactivate in under one hour, ${ }^{48-50}$ highlighting the relative stability of Ni-CFA-1. We believe this increased catalytic stability is due to the site isolation of the catalyst within the metal-organic framework, inhibiting bimolecular decomposition pathways. 
Ni-CFA-1 is a rare example of a heterogeneous catalyst that is both active and selective for ethylene dimerization. Despite the reduced synthetic challenges, the catalytic performance of $\mathrm{Ni}$ CFA-1 is similar to that of the related, but synthetically less accessible Ni-MFU- $4 l$. Both catalysts are increasingly selective for 1-butene as the ethylene pressure increases, and at similar nickel loading levels the activity of Ni-CFA-1 and Ni-MFU-4l are comparable. Many other heterogeneous catalysts have been explored for ethylene dimerization, ${ }^{41-43}$ to which Ni-CFA-1 compares favorably. Although a number of Ni-based zeolite or mesoporous silica ethylene oligomerization catalysts show a high stability against deactivation, many are poorly selective for 1-butene. ${ }^{51-53} \mathrm{Ni}-\mathrm{MCM}-41$, the only such catalyst with an activity and selectivity similar to NiCFA-1, is exclusively stable at subambient temperatures (less than $-15^{\circ} \mathrm{C}$ ) that present substantial practical challenges. ${ }^{53}$ By demonstrating sustained selective ethylene dimerization at ambient temperatures, Ni-CFA-1 represents an improvement on the existing technology and a step towards commercial heterogeneous catalysts for ethylene dimerization.

\section{Conclusions}

In summary, we have shown that the deactivation of MOF catalysts prepared by cation exchange can be both understood and mitigated, in a manner amenable to systematic catalyst improvement in the solid state. Through this process, we have developed Ni-CFA-1 as a robust and scalable catalyst for ethylene dimerization, whose selectivity and activity as a solid catalyst is only matched by Ni-MCM-41 and the related Ni-MFU- $4 l$. We anticipate that these results will be relevant for the heterogeneous dimerization of ethylene industrially by highlighting the potential of an easily prepared MOF catalyst for this challenging reaction.

\section{ASSOCIATED CONTENT}




\section{Supporting Information.}

The Supporting Information is available free of charge on the ACS Publications website.

Experimental details, structural comparisons of MFU-4l and CFA-1, XAS data, cost analysis of MFU-4l and CFA-1, gas chromatograms, and NMR data (PDF)

\section{AUTHOR INFORMATION}

\section{Corresponding Author}

* Corresponding Author: Mircea Dincă, mdinca@mit.edu

\section{Present Addresses}

$†$ Present address: Laboratory of Inorganic Chemistry, ETH Zürich, Vladimir Prelog Weg 1, CH8093 Zürich, Switzerland

\section{Author Contributions}

\$ E.D.M and R. J. C. contributed equally to this work.

\section{Funding Sources}

Saudi-Aramco

National Science Foundation (DMR-1452612) 


\section{ACKNOWLEDGMENT}

This research was supported through a Research Agreement with Saudi Aramco, a Founding Member of the MIT Energy Initiative. Fundamental studies of cation exchange in MOFs are sponsored through a CAREER grant to M.D. from the National Science Foundation (DMR1452612). Z. W., G. Z., J. T. M. are supported in part by the National Science Foundation under Cooperative Agreement No. EEC-1647722. Any opinions, finding, and conclusions or recommendations expressed in this material are those of the authors and do not necessarily reflect the views of the National Science Foundation. Use of the Advanced Photon Source was supported by the U. S. Department of Energy, Office of Basic Energy Sciences, under contract no. DE-AC0206CH11357. MRCAT operations, beamline 10-ID, are supported by the Department of Energy and the MRCAT member institutions. We thank Dr. Maciej Korzyński for experimentally validating dimerization results and Chenyue Sun for assistance with ICP-MS measurements. 


\section{REFERENCES}

(1) Xiao, D. J.; Bloch, E. D.; Mason, J. A.; Queen, W. L.; Hudson, M. R.; Planas, N.; Borycz, J.; Dzubak, A. L.; Verma, P.; Lee, K.; Bonino, F.; Crocellà, V.; Yano, J.; Bordiga, S.; Truhlar, D. G.; Gagliardi, L.; Brown C. M.; Long, J. R. Oxidation of Ethane to Ethanol by $\mathrm{N}_{2} \mathrm{O}$ in a Metal-Organic Framework with Coordinatively Unsaturated iron(II) Sites. Nat. Chem. 2014, 6 (7), 590-595.

(2) Farrusseng, D.; Aguado, S.; Pinel, C. Metal-Organic Frameworks: Opportunities for Catalysis. Angew. Chem. Int. Ed. 2009, 48 (41), 7502-7513.

(3) Mondloch, J. E.; Katz, M. J.; Isley III, W. C.; Ghosh, P.; Liao, P.; Bury, W.; Wagner, G. W.; Hall, M. G.; DeCoste, J. B.; Peterson, G. W.; Snurr, R. Q.; Cramer, C. J.; Hupp, J. T.; Farha, O. K. Destruction of Chemical Warfare Agents Using Metal-organic Frameworks. Nat. Mater. 2015, 14, 512-516.

(4) Gascon, J.; Corma, A.; Kapteijn, F.; Llabre, F. X. Metal Organic Framework Catalysis: Quo Vadis? ACS Catal. 2014, 4, 361-378.

(5) Ma, L.; Falkowski, J. M.; Abney, C.; Lin, W. A Series of Isoreticular Chiral Metal-Organic Frameworks as a Tunable Platform for Asymmetric Catalysis. Nat. Chem. 2010, 2 (10), 838-846.

(6) Liu, B.; Jie, S.; Bu, Z.-Y.; Li, B.-G. Postsynthetic Modification of Mixed-Linker MetalOrganic Frameworks for Ethylene Oligomerization. RSC Adv. 2014, 4, 62343-62346.

(7) Fei, H.; Cohen, S. M. A Robust, Catalytic Metal-organic Framework with Open 2,2'Bipyridine Sites. Chem. Commun. 2014, 50 (37), 4810-4812.

(8) Wang, C.; Xie, Z.; deKrafft, K. E.; Lin, W. Doping Metal Organic Frameworks for Water Oxidation, Carbon Dioxide Reduction, and Organic Photocatalysis. J. Am. Chem. Soc. 2011, 133, 13445-13454.

(9) Wu, C.; Hu, A.; Zhang, L.; Lin, W. A Homochiral Porous Metal - Organic Framework for Highly Enantioselective Heterogeneous Asymmetric Catalysis A Homochiral Porous Metal-Organic Framework for Highly Enantioselective. J. Am. Chem. Soc. 2005, 127, 8940-8941.

(10) Fei, H.; Shin, J.; Meng, Y. S.; Adelhardt, M.; Sutter, J.; Meyer, K.; Cohen, S. M. Reusable Oxidation Catalysis Using Metal-Monocatecholato Species in a Robust Metal-Organic Framework. J. Am. Chem. Soc. 2014, 136 (13), 4965-4973. 
(11) Wang, H.-L.; Yeh, H.; Chen, Y.-C.; Lai, Y.-C.; Lin, C.-Y.; Lu, K.-Y.; Ho, R.-M.; Li, B.H.; Lin, C.-H.; Tsai, D.-H. Thermal Stability of Metal-Organic Frameworks and Encapsulation of $\mathrm{CuO}$ Nanocrystals for Highly Active Catalysis. ACS Appl. Mater. Interfaces 2018, 10 (11), 9332-9341.

(12) Montoro, C.; Linares, F.; Quartapelle Procopio, E.; Senkovska, I.; Kaskel, S.; Galli, S.; Masciocchi, N.; Barea, E.; Navarro, J. A. R. Capture of Nerve Agents and Mustard Gas Analogues by Hydrophobic Robust MOF-5 Type Metal-Organic Frameworks. J. Am. Chem. Soc. 2011, 133 (31), 11888-11891.

(13) Park, K. S.; Ni, Z.; Côté, A. P.; Choi, J. Y.; Huang, R.; Uribe-Romo, F. J.; Chae, H. K.; O'Keeffe, M.; Yaghi, O. M. Exceptional Chemical and Thermal Stability of Zeolitic Imidazolate Frameworks. Proc. Natl. Acad. Sci. U. S. A. 2006, 103 (27), 10186-10191.

(14) Cavka, J. H.; Jakobsen, S.; Olsbye, U.; Guillou, N.; Lamberti, C.; Bordiga, S.; Lillerud, K. P. A New Zirconium Inorganic Building Brick Forming Metal Organic Frameworks with Exceptional Stability. J. Am. Chem. Soc. 2008, 130 (42), 13850-13851.

(15) Colombo, V.; Galli, S.; Choi, H. J.; Han, G. D.; Maspero, A.; Palmisano, G.; Masciocchi, N.; Long, J. R. High Thermal and Chemical Stability in Pyrazolate-Bridged Metal-organic Frameworks with Exposed Metal Sites. Chem. Sci. 2011, 2 (7), 1311-1319.

(16) Gonzalez, M. I.; Oktawiec, J.; Long, J. R. Ethylene Oligomerization in Metal-organic Frameworks Bearing Nickel(II) 2,2'-Bipyridine Complexes. Faraday Discuss. 2017, 201, $351-367$.

(17) Liu, S.; Zhang, Y.; Huo, Q.; He, S.; Han, Y. Synthesis and Catalytic Performances of a Novel Zn-MOF Catalyst Bearing Nickel Chelating Diimine Carboxylate Ligands for Ethylene Oligomerization. J. Spectroscopy [Online] 2015, Article 310162, http://dx.doi.org/10.1155/2015/310162.

(18) Canivet, J.; Aguado, S.; Schuurman, Y.; Farrusseng, D. MOF-Supported Selective Ethylene Dimerization Single-Site Catalysts through One-Pot Postsynthetic Modification. J. Am. Chem. Soc. 2013, 135 (11), 4195-4198.

(19) Madrahimov, S. T.; Gallagher, J. R.; Zhang, G.; Meinhart, Z.; Garibay, S. J.; Delferro, M.; Miller, J. T.; Farha, O. K.; Hupp, J. T.; Nguyen, S. T. Gas-Phase Dimerization of Ethylene under Mild Conditions Catalyzed by MOF Materials Containing (bpy)Ni ${ }^{\mathrm{II}}$ Complexes. $A C S$ Catal. 2015, 5, 6713-6718.

(20) Ye, J.; Gagliardi, L.; Cramer, C. J.; Truhlar, D. G. Single Ni Atoms and Ni4 Clusters Have Similar Catalytic Activity for Ethylene Dimerization. J. Catal. 2017, 354, 278-286.

(21) Bernales, V.; League, A. B.; Li, Z.; Schweitzer, N. M.; Peters, A. W.; Carlson, R. K.; Hupp, 
J. T.; Cramer, C. J.; Farha, O. K.; Gagliardi, L. Computationally Guided Discovery of a Catalytic Cobalt-Decorated Metal-Organic Framework for Ethylene Dimerization. J. Phys. Chem. C 2016, 120 (41), 23576-23583.

(22) Li, Z.; Schweitzer, N. M.; League, A. B.; Bernales, V.; Peters, A. W.; Getsoian, A. "Bean"; Wang, T. C.; Miller, J. T.; Vjunov, A.; Fulton, J. L.; et al. Sintering-Resistant Single-Site Nickel Catalyst Supported by Metal-Organic Framework. J. Am. Chem. Soc. 2016, 138 (6), 1977-1982.

(23) Yang, D.; Odoh, S. O.; Wang, T. C.; Farha, O. K.; Hupp, J. T.; Cramer, C. J.; Gagliardi, L.; Gates, B. C. Metal-Organic Framework Nodes as Nearly Ideal Supports for Molecular Catalysts: NU-1000- and UiO-66-Supported Iridium Complexes. J. Am. Chem. Soc. 2015, 137 (23), 7391-7396.

(24) Mlinar, A. N.; Keitz, B.; Gygi, D.; Bloch, E.; Long, J. R.; Bell, A.T . Selective Propene Oligomerization with Nickel(II)-Based Metal-Organic Frameworks. ACS Catal. 2014, 4, $717-721$.

(25) Kaskel, S.; Kutzscher, C.; Senkovska, I. Towards Highly Active and Stable Nickel-Based Metal-organic Frameworks as Ethylene Oligomerization Catalysts. Dalton Trans. [Online early access]. DOI: 10.1039/c8dt03866j. Published online: Feb. 13, 2019.

(26) Metzger, E. D.; Comito, R. J.; Hendon, C. H.; Dincă, M. Mechanism of Single-Site Molecule-Like Catalytic Ethylene Dimerization in Ni-MFU-4l. J. Am. Chem. Soc. 2017, 139 (2), 757-762.

(27) Metzger, E. D.; Brozek, C. K.; Comito, R. J.; Dincă, M. Selective Dimerization of Ethylene to 1-Butene with a Porous Catalyst. ACS Cent. Sci. 2016, 2 (3), 148-153.

(28) Comito, R. J.; Fritzsching, K. J.; Sundell, B. J.; Schmidt-Rohr, K.; Dincă, M. Single-Site Heterogeneous Catalysts for Olefin Polymerization Enabled by Cation Exchange in a MetalOrganic Framework. J. Am. Chem. Soc. 2016, 138 (32), 10232-10237.

(29) Dubey, R. J.-C.; Comito, R. J.; Wu, Z.; Zhang, G.; Rieth, A. J.; Hendon, C. H.; Miller, J. T.; Dincă, M. Highly Stereoselective Heterogeneous Diene Polymerization by Co-MFU-4l : A Single-Site Catalyst Prepared by Cation Exchange. J. Am. Chem. Soc. 2017, 139 (36), 12664-12669.

(30) Denysenko, D.; Grzywa, M.; Jelic, J.; Reuter, K.; Volkmer, D. Scorpionate-Type Coordination in MFU-4l Metal-Organic Frameworks: Small-Molecule Binding and Activation upon the Thermally Activated Formation of Open Metal Sites. Angew. Chemie Int. Ed. 2014, 53 (23), 5832-5836.

(31) Denysenko, D.; Werner, T.; Grzywa, M.; Puls, A.; Hagen, V.; Eickerling, G.; Jelic, J.; Reuter, K.; Volkmer, D. Reversible Gas-Phase Redox Processes Catalyzed by CoExchanged MFU-4l(arge). Chem. Commun. 2012, 48 (9), 1236-1238. 
(32) Denysenko, D.; Jelic, J.; Reuter, K.; Volkmer, D. Postsynthetic Metal and Ligand Exchange in MFU-4l: A Screening Approach toward Functional Metal-Organic Frameworks Comprising Single-Site Active Centers. Chem. - A Eur. J. 2015, 21 (22), 8188-8199.

(33) Brozek, C. K.; Bellarosa, L.; Soejima, T.; Clark, T. V.; López, N.; Dincă, M. SolventDependent Cation Exchange in Metal-Organic Frameworks. Chem. - A Eur. J. 2014, 20 (23), 6871-6874.

(34) Comito, A. R.; Wu, Z.; Zhang, G.; Korzynski, M.; Kehl, J. A.; Miller, J. Stabilized Vanadium Catalyst for Olefin Polymerization by Site-Isolation in a Metal-Organic Framework. Angew. Chem. Int. Ed. 2018, 57, 8135-8139.

(35) The Co-MFU-4l sample used here had the composition $\mathrm{Co}_{4} \mathrm{ZnCl}_{4}(\mathrm{BTDD})_{3}$, and thus no pore-exposed sites available for reaction with $\mathrm{AlMe}_{3}$ or MMAO-12. See section S2 for a full node structure of these two MOFs.

(36) Camacho-Bunquin, J.; Aich, P.; Ferrandon, M.; Getsoian, A. "B."; Das, U.; Dogan, F.; Curtiss, L. A.; Miller, J. T.; Marshall, C. L.; Hock, A. S.; et al. Single-Site Zinc on Silica Catalysts for Propylene Hydrogenation and Propane Dehydrogenation: Synthesis and Reactivity Evaluation Using an Integrated Atomic Layer Deposition-Catalysis Instrument. J. Catal. 2017, 345, 170-182.

(37) Koller, J.; Bergman, R. G. Controlled Hydrosilylation of Carbonyls and Imines Catalyzed by a Cationic Aluminum Alkyl Complex. Organometallics 2012, 31 (7), 2530-2533.

(38) Looney, A.; Parkin, G. Poly(pyrazolyl)hydroborato and Poly(pyrazolyl)methane Aluminium Alkyl Derivatives. Polyhedron 1990, 9 , 265-276.

(39) Comito, R. J.; Metzger, E. D.; Wu, Z.; Zhang, G.; Hendon, C. H.; Miller, J. T.; Dincă, M. Selective Dimerization of Propylene with Ni-MFU-4l. Organometallics 2017, 36 (9), 16811683.

(40) Schmieder, P.; Denysenko, D.; Grzywa, M.; Baumgärtner, B.; Senkovska, I.; Kaskel, S.; Sastre, G.; van Wüllen, L.; Volkmer, D. CFA-1: The First Chiral Metal-organic Framework Containing Kuratowski-Type Secondary Building Units. Dalt. Trans. 2013, 42 (30), 1078610797.

(41) Owing to the disordered anion composition of Ni-CFA-1, the incorporation of $\mathrm{Ni}^{2+}$ into the SBU of this MOF could not be characterized by EXAFS in the same way that we have done for Ni-MFU-4l.

(42) Prepared by multiple cycles of dissolution in hexane followed by vacuum evacuation. See section S7 and Zijlstra, H. S.; Harder, S. Methylalumoxane - History, Production, Properties, and Applications. Eur. J. Inorg. Chem. 2015, 19-43. 
(43) Tritto, I.; Méalares, C.; Sacchi, M. C.; Locatelli, P. Methylaluminoxane: NMR Analysis, Cryoscopic Measurements and Cocatalytic Ability in Ethylene Polymerization. Macromol. Chem. Phys. 1997, 198 (12), 3963-3977.

(44) Talarico, G.; Budzelaar, P. H. M. Variability of Chain Transfer to Monomer Step in Olefin Polymerization. Organometallics 2008, 27 (16), 4098-4107.

(45) Rappé, A. K.; Skiff, W. M.; Casewit, C. J. Modeling Metal-Catalyzed Olefin Polymerization. Chem. Rev. 2000, 100, 1435-1456.

(46) Deng, L.; Woo, T. K.; Cavallo, L.; Margl, P. M.; Ziegler, T.; The Role of Bulky Substituents in Brookhart-Type Ni(II) Diimine Catalyzed Olefin Polymerization : A Combined Density Functional Theory and Molecular Mechanics Study. J. Am. Chem. Soc. 1997, 119, 61776186.

(47) Froese, R. D. J.; Musaev, D. G.; Morokuma, K. Molecular Orbital and IMOMM Studies of the Chain Transfer Mechanisms of the Diimine-M(II)-Catalyzed (M-Ni, Pd) Ethylene Polymerization Reaction. Organometallics, 1998, 17, 1850-1860.

(48) Al-Sa'doun, A. W. Dimerization of Ethylene to Butene-1 Catalyzed by Ti(OR') $)_{4}-\mathrm{AlR}_{3}$. Appl. Catal., A: Gen. 1993, 105, 1-40.

(49) Schmidt, R.; Saudi Basic Industries Corporation; Catalyst Compositions for Ethylene Dimerization, US 2016/0325274 A1, November 10, 2016.

(50) Smith, P. D.; Klendworth, D. D.; McDaniel, M. P. Ethylene Dimerization over Supported Titanium Alkoxides. J. Catal. 1987, 105, 187-198.

(51) Finiels, A.; Fajula, F.; Hulea, V. Nickel-based solid catalysts for ethylene oligomerization - a review. Catal. Sci. Technol. 2014, 4 (8), 2412-2426.

(52) Hulea, V. Towards Platform Chemicals from Bio-Based Ethylene: Heterogeneous Catalysts and Processes. ACS Catal. 2018, 8 (4), 3263-3279.

(53) Agirrezabal-Telleria, I.; Iglesia, E. Stabilization of Active, Selective, and Regenerable NiBased Dimerization Catalysts by Condensation of Ethene Within ordered Mesopores. $J$. Catal. 2017, 352, 505-514. 


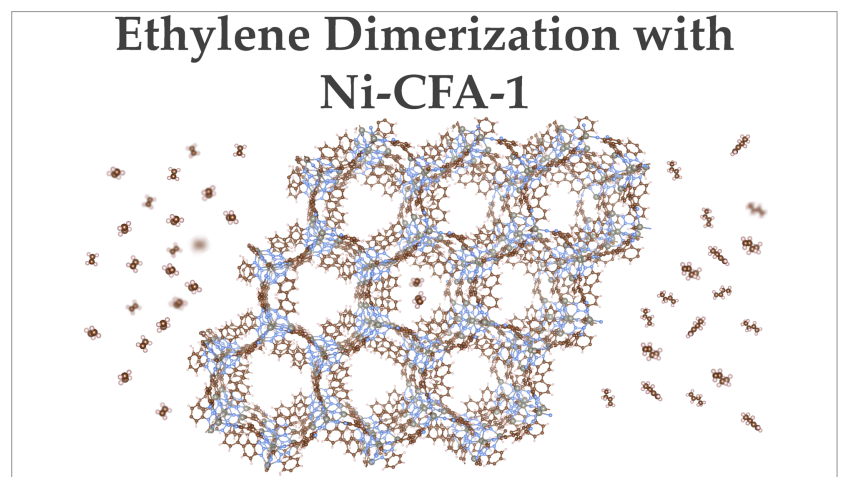

Synopsis

Ni-CFA-1 is a synthetically accessible catalyst for ethylene dimerization, providing a heterogeneous alternative to the current industrial homogeneous catalyst. 